\title{
Perceptions of quality and safety among dental patients
}

SADJ August 2019, Vol. 74 No. 7 p374 - p382

E Obadan-Udoh', R Ramoni' ${ }^{2}$, S Van Der Berg-Cloete ${ }^{3}$, G White ${ }^{4}$, E Kalenderian ${ }^{5}$

\begin{abstract}
Introduction

From the perspective of patients, quality of care can be defined as the ability of healthcare products and services to satisfy their stated or implied needs. Dental professionals have a moral obligation to deliver the best quality care in today's increasingly informed, consumer-driven society.
\end{abstract}

\section{Aim}

To jumpstart the discussion on assessing quality of dental care, using patient perceptions.

\section{Design}

A cross-sectional study of South African dental patients.

\section{Methods}

Questionnaires were distributed to all non-emergency, adult patients at a teaching dental hospital in South Africa.

The outcome variables were:
a) Access to Care;
b) Technical Quality;
c) Structure and Facilities;
d) Communication;
e) Global Rating of Safety.

\section{Author affiliations:}

1. Enihomo Obadan-Udoh: DDS, MPH, Dr. Med. Sc, Department of Preventive and Restorative Dental Sciences, School of Dentistry, University of California San Francisco, California, USA ORCID Number: 0000-0002-1005-7241

2. Rachel Ramoni: $D M D, S c D$, Department of Epidemiology and Health Promotion, School of Dentistry, New York University, New York, USA.

ORCID Number: 0000-0002-1459-9638

3. Sophy Van Der Berg-Cloete: BChD, MBA, DHSM, Department of Dental Management Sciences, School of Dentistry, University of Pretoria, Pretoria, South Africa. ORCID Number: 0000-0001-7560-1095

4. George White: $B C h D, M B A, P h D$, Department of Dental Management Sciences, School of Dentistry, University of Pretoria, Pretoria, South Africa.

5. Elsbeth Kalenderian: $D D S, M P H, P h D$, Department of Preventive and Restorative Dental Sciences, School of Dentistry, University of California San Francisco, California, USA. ORCID Number: 0000-0002-4684-9793

Corresponding author: Enihomo Obadan-Udoh

Department of Preventive and Restorative Dental Sciences, School of Dentistry, University of California San Francisco, 3333 California St.,

Ste. 495, CA 94118, USA; 415.502.6508

Email: enihomo.obadan-udoh@ucsf.edu

Author contributions:

Enihomo Obadan-Udoh: Principal researcher - 50\%

Rachel Ramoni: Advisor - 10\%

3. Sophy Van Der Berg-Cloete: Co-investigator - $20 \%$

George White: Advisor - 10\%

5. Elsbeth Kalenderian: Advisor - 10\%

\author{
ACRONYMS \\ ADA: American Dental Association \\ CQI: $\quad$ Consumer Quality Index \\ DAEs: Dental Adverse Events \\ DQA: Dental Quality Alliance \\ DQOF: Dental Quality and Outcomes Framework \\ IOM: Institute of Medicine \\ NIDCR: National Institute of Dental \\ and Craniofacial Research \\ NIH: $\quad$ National Institutes of Health \\ PES: $\quad$ Patient Experience Survey \\ PRR: Prevalence Rate Ratios \\ QUOTE: Quality of care through the patient's eyes
}

\section{Results}

Overall, $58.6 \%$ of the participants had a positive view about the quality of dental care in South Africa. Age, race, marital status, child status, employment status, household income and educational status were associated with higher quality ratings.

The question: "The instrument used in treating me appeared clean" (97.6\%) was rated highly, while the question "Whenever I was sent to a new dentist, I had to repeat the tests that I did at the previous dentist" rated very low (36.9\%).

\section{Conclusions}

The findings suggest that the dental profession still has challenges in meeting the expectations of patients.

\section{Keywords}

Healthcare quality, patient safety, patient-reported outcome measures, dental care.

\section{INTRODUCTION}

From the patient's perspective, quality of care can be defined as the ability of healthcare products and services to satisfy their stated or implied needs. ${ }^{1}$ As defined by the Committee on Healthcare Quality in America, Institute of Medicine (IOM), one of the seven aims for healthcare quality is Patient-centered Care ("providing care that is respectful of and responsive to individual patient preferences, needs and values, and ensuring that patient values guide all clinical decisions"). ${ }^{2}$

The committee further describes the core dimensions of patient-centered care as: 1) Respect for patient values, attention to patient preferences and expressed needs; 2) Coordination and integration of care; 3) Information, communication and education; 
4) Physical comfort; 5) Emotional support: relieving fear and anxiety, 6) Involvement of family and friends, 7) Transition and continuity. ${ }^{2}$ The Picker Institute lists similar concepts as the most important priorities for patients in healthcare but adds an eighth dimension, namely: Access to care. ${ }^{3}$

Specifically pertaining to ambulatory care, the following are described as conditions: Access to the location of hospitals, clinics and physician offices; Availability of transportation; Ease of scheduling appointments; Availability of appointments when needed; Accessibility to specialists or specialty services when a referral is made; Clear instructions provided on when and how to be referred. ${ }^{4}$

Most of these dimensions for patient-centered care were first described by Gerteis et al. in 1993 when they identified the key factors in patient-centered care as: Respect for patients views, preferences and expressed needs; Co-ordination and integration of care; Information, communication and education; Physical comfort; Emotional support and alleviation of fear and anxiety; Involvement of family and friends; Transition and continuity. ${ }^{5}$

The concept of patient-centered care often creates a conflict between patients and providers because patients prioritize different aspects of the care $^{6-8}$ and these priorities may influence their perceptions of quality of care. ${ }^{9}$ Whilst some would argue that patient perceptions are subjective and therefore unreliable,,$^{10,11}$ others believe in the inherent value of these assessments because the patient is the primary recipient of care and therefore has the most important perspective. ${ }^{12}$

They posit that there is indeed an instrumental value to patient perceptions of quality due to the far-reaching consequences on the choice of providers or health plans, compliance with medical advice, health outcomes and the expression of grievances or seriousness of malpractice claims. ${ }^{9,12-16}$ Therein lies the dilemma between the subjective versus normative assessments of quality in healthcare..$^{9,17}$ Some researchers have proposed shifting the focus from patient satisfaction, a narrow and relative concept ${ }^{1,18}$ to a more substantive and robust evaluation of patient perceptions of quality, using tools that measure the actual experiences of care..$^{1,9,17,19-23}$ The development of the appropriate tools is still at its infancy, as is also the concept of patient-centeredness and its applications to quality of dental care..$^{24-27}$

In addition to the above-mentioned reasons, the desire to promote greater transparency and accountability of healthcare systems underscores the importance of quality measurement. ${ }^{9}$ As dental professionals, we have a moral obligation to deliver the best quality care that meets both professional standards and patient needs, the latter especially so, in an increasingly informed, consumer-driven society. ${ }^{10,28}$

The American Dental Association (ADA) through the Dental Quality Alliance (DQA $)^{29,30}$ and the United Kingdom Department of Public Health through the Dental Quality and Outcomes Framework (DQOF) ${ }^{31,32}$ have laid the foundation for the development of quality metrics in dentistry. ${ }^{27}$ Efforts are also ongoing by the second and fifth authors of this paper through grant funding from the National Institutes of Health $(\mathrm{NIH}) /$ National Institute of Dental and Craniofacial Research (NIDCR) - R01DE0 24166-01A1, to implement dental quality measures in dental practices across the United States (US). ${ }^{33}$

The goal of this paper is to jumpstart the discussion on patient perceptions of quality as a useful tool for assessing the quality dental care. In the future, this will offer the profession a screening tool for the quick evaluation of dental practices for high performance or for the identification of areas in need of improvement.

Subsequent steps will involve defining key concepts and outcome measures for patient-reported dental quality as well as developing standardized instruments for measuring that quality.

Surveys have typically been used to garner information about patient perceptions of quality. . $^{9,34} \mathrm{~A}$ national survey of dental patients in the United Kingdom by Tickle et al. showed that about one fifth of respondents rated the quality of dental care they received as suboptimal. ${ }^{35}$

The factors that were important in their assessment of quality were: "access (40\%), technical quality of care (35\%), professionalism (30\%), hygiene/cleanliness (30\%), staff attitude (27\%), pain-free treatment (23\%), value for money (22\%), and staff putting patients at ease (21\%)". ${ }^{35}$ Positive responses were associated with "good interpersonal communication, politeness and being put at ease" while negative responses were associated with poor wait times and high cost of care. ${ }^{35}$

This study used a self-reported survey to assess the quality of care experience among South African dental patients.

\section{METHODS}

\section{Survey design}

The survey was developed by the authors through an iterative process and tested for validity and reliability. A simple convenience sampling method was used to collect information from all non-emergency, adult patients (>18 years) at a teaching dental hospital in South Africa.

Patients gave their informed consent after reading an information leaflet detailing the research objectives and by completing the survey. Necessary approvals were obtained from the Ethics Committees at the University of Pretoria and the Harvard School of Dental Medicine prior to the commencement of data collection.

\section{Definitions and measures}

The questionnaire was subdivided into five main sections: 1) Past dental history and oral health, 2) Quality of past dental care, 3) Experience of dental adverse events (DAEs), 4) Sequelae and follow-up events after DAE experience, and 5) Biographic data. 
Results from sections 3 and 4 are discussed in another paper. This manuscript primarily focuses on section 2 (Quality of past dental care) but utilizes variables from sections 1 and 5 for explanatory purposes.

\section{Outcome variables}

The five primary outcome variables were: a) Access to Care (7 items); b) Technical Quality, Efficiency and Effective Organization of Care (10 items); c) Structure and Facilities (6 items); d) Communication, Information and Courtesy (10 items); e) Global rating of safety. The first four outcome variables were obtained by classifying the questions from section 2 into patient-defined dimensions of quality identified by Sofaer et al. in their extensive review titled "Patient Perceptions of Quality". ${ }^{9}$

The original seven dimensions were: 1) patient-centered care; 2) access; 3) communication and information;

4) courtesy and emotional support; 5) technical quality; 6) efficiency of care/organization; and 7) structure and facilities. ${ }^{9}$ Each variable was assessed using items that were measured on a 5-point Likert scale ranging from 1 (Always), 2 (Usually), 3 (Sometimes), 4 (Never), and 5 (Not Applicable).

\begin{tabular}{ll}
\hline Table 1. Reliability (Internal consistency) & \multicolumn{1}{c}{$\begin{array}{c}\text { Cronbach's } \\
\alpha \text { coefficient }\end{array}$} \\
\hline Dimensions of quality & 0.62 \\
\hline A) Access to Care & 0.83 \\
\hline $\begin{array}{l}\text { B) Technical Quality, Efficiency and Effective } \\
\text { Organization of Care }\end{array}$ & 0.71 \\
\hline C) Structure and Facilities & 0.92 \\
\hline D) Communication, Information and Courtesy & 0.77 \\
\hline Overall &
\end{tabular}

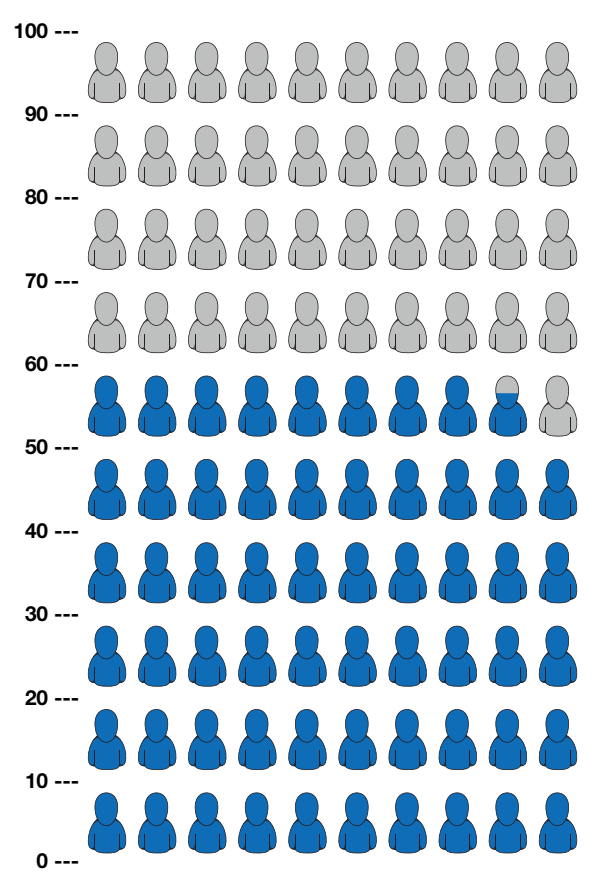

58.6 out of 100 people rated the quality of dental care as high.

Figure 1. Overall perception of dental quality.

Legend: Pictorial representation of the percentage of patients who rated the quality of dental care received as high $(58.6 \%)$
The final responses were collapsed into a 4-point scale and reverse coded to be more intuitive (negative responses were assigned lower values and vice versa). Option 5 (Not applicable) was treated as missing. All four categories had a combined Cronbach's alpha of 0.77 (acceptable) for internal validity (Table 1).

The fifth outcome variable (global rating of safety) was generated from the question "In general, how safe are the dental clinics that you have visited in South Africa?" This question was assessed on a 10 -point visual analog scale and collapsed into five categories ranging from 1 (extremely unsafe) to 5 (extremely safe).

\section{Explanatory variables}

The past dental history, dental and overall health status, and oral hygiene practices were assessed. We also assessed the relationship between demographic factors such as: gender, age, race, educational level, economic status, employment status, marital status and number of children on each outcome variable.

\section{Statistical analysis}

All statistical analyses were performed using STATA $14 \circledast$. Percent positives were obtained by collapsing the upper two response options for each line item ('Always' and 'Usually' or 'Extremely safe' and 'Safe' for category 5) (Table 2). For inferential analyses, the five categories were converted into binary variables (low vs. high quality) using the mean scores as the cut-off point.

Bivariate analyses using Pearson's chi-squared test were used to identify the explanatory variables with significant relationships with the outcome variables (Table 3).

Further statistical analyses were performed using generalized linear models of the Poisson family with robust variance estimates to generate adjusted prevalence rate ratios (PRR) and identify significantly associated variables with the dimensions of quality and safety.

\section{RESULTS}

440 questionnaires were returned (97.8\% response rate). The sample characteristics are given as follows: Females (62.7\%), 25-44 years (47.8\%), whites (64.9\%), unemployed $(45.8 \%)$, high school or vocational school education $(52.5 \%)$, had children $(67.8 \%)$, single-never married (36.1\%), low income household (57.8\%), dental visit within previous 12 months (52.2\%), visited a state dental clinic for last dental visit (57.7\%), satisfied or extremely satisfied with last dental visit (69.1\%), not satisfied with dental health (57.7\%), satisfied with overall health $(85.1 \%)$, clean teeth at least once daily (94.3\%) and uses a toothbrush with fluoride or non-fluoride toothpaste (57.3\%).

\section{Overall perception of quality and safety}

Figure 2 shows the percentage of participants who had positive perceptions of quality and safety by dimension. Access to care received the least favourable rating 
Table 2. Detailed Dimensions of Dental Quality and Safety, showing Percentage Positive and Mean scores.

Dimensions of quality

\section{A) Access to care}

I was able to get an appointment within $24 \mathrm{hrs}$ for a dental emergency. $(95 \% \mathrm{Cl})$

I was able to get an appointment within one month of my preferred date for routine check-up/cleaning.

I was able to get an appointment within one month of my preferred date to see a dental specialist (e.g. for surgery).

I got turned away when I could not afford to pay for my dental treatment*.

I had to travel more than 45 minutes to get to the dental clinic*.

I was able to see the dental provider within one hour of my appointment.

I found it hard getting into the dental clinic because of my physical disability*.

$55.3(49.8-60.7)$

59.7 (54.3 - 65.2)

$58.4(52.5-64.3)$

$77.8(72.6-83.0)$

$56.3(50.8-61.8)$

$46.7(41.1-52.2)$

$91.6(86.9-96.2)$

$84.8(81.1$ - 88.5)

$74.6(70.1-79.2)$

$66.6(61.6-71.6)$

$65.8(60.6-70.9)$

$74.3(69.6-78.9)$

$93.3(90.6-96.0)$

$87.9(84.2-91.5)$

$78.0(73.2-82.8)$

$56.0(50.1-61.8) \quad 2.7 \pm 1.2$

$36.9(31.0-42.8)$

$95.9(93.8-98.0)$

$91.1(88.0-94.2)$

$97.6(95.9-99.3)$

92.5 (89.6 - 95.4)

93.4 (90.5 - 96.2)

$92.0(89.0-95.0)$

$89.0(85.6-92.4)$

$89.0(85.6$ - 92.4)

87.7 (84.2 - 91.3)

88.9 (85.5 - 92.3)

87.1 (83.4 - 90.8)

89.1 (85.7 - 92.5)

$85.2(81.2-89.1)$

88.6 (85.2 - 91.9)

94.6 (92.3 - 97.0)

88.6 (85.2 - 92.0)

86.7 (82.8 - 90.6)

$83.9(79.3-88.5)$

$\pm 0.9$

$3.1 \pm 1.1$

$2.9 \pm 1.1$

$2.9 \pm 1.2$

$3.1 \pm 1.0$

$3.6 \pm 0.7$

$3.5 \pm 0.8$

$3.2 \pm 1.1$

$2.1 \pm 1.1$

$3.7 \pm 0.6$

$3.6 \pm 0.7$

$3.8 \pm 0.5$

$3.6 \pm 0.7$

$3.8 \pm 0.7$

$3.7 \pm 0.7$

$3.5 \pm 0.7$

$3.4 \pm 0.8$

$3.5 \pm 0.8$

$3.4 \pm 0.8$

$3.5 \pm 0.8$

$3.4 \pm 0.9$

$3.6 \pm 0.8$

$3.7 \pm 0.6$

$3.5 \pm 0.8$

$3.5 \pm 0.8$

$8.15 \pm 2.07$
Mean \pm SD

$2.6 \pm 1.1$

$2.7 \pm 1.0$

$2.6 \pm 1.1$

$3.3 \pm 1.1$

$2.6 \pm 1.2$

$2.5 \pm 1.0$

$3.7 \pm 0.8$

Whenever I was sent to a new dentist, the purpose of the referral was very clear to me.

\section{E) Global rating of safety}

On a scale of 1 to 10 , with 1 being 'extremely unsafe' and 10 being 'extremely safe', how safe (harmless) are the dental clinics that you have visited in South Africa?

Percentage positives were obtained by combing the responses from all participants who responded with "always" (4) or "usually"(3) on the Likert scale (1 to 4); the higher the percentage, the more positive the experience; Percent positives for each construct represent the percentage of participants who selected the two highest response options for each line item ('Always' and 'Usually' or 'Extremely safe' and 'Safe' for category 5); $\S$ The mean score represents the average score obtained from all participants for every item on the Likert scale (1 to 4$)$. Higher values represent more positive experiences by participants;

${ }^{*}$ Original items were reverse-coded for data analysis to mirror the other items, which ranged from the least positive (1) to the most positive (4) experience.

of quality (mean score: $2.8 \pm 0.68$ ). Only $48.6 \%$ of participants rated this dimension as high quality. The global rating of safety received the highest score (mean score: $4.3 \pm 0.98)$; over $80 \%$ of participants had a positive perception of safety.

This rating was not correlated with their past experiences of DAEs (Pearson's rho (r): -0.21 ). Overall, slightly above half $(58.6 \%)$ of the participants had a positive view about the quality of dental clinics in South Africa.
The item "Whenever I was sent to a new dentist, I had to repeat the tests that I did at the previous dentist" received the lowest percentage positive score $(36.9 \%$; 95\% Cl: 31.0-42.8), while the item "The instruments used in treating me appeared clean" received the highest score (97.6\%; 95\% Cl: 95.9-99.3) (Table 2). 


\begin{tabular}{|c|c|c|c|c|c|c|}
\hline Characteristic & Total, $N(\%)$ & Access to care & $\begin{array}{l}\text { Technical } \\
\text { quality }\end{array}$ & $\begin{array}{l}\text { Structure \& } \\
\text { facilities }\end{array}$ & Communication & $\begin{array}{l}\text { Global safety } \\
\text { rating }\end{array}$ \\
\hline Total, N & 440 & 389 & 383 & 376 & 374 & 249 \\
\hline Mean $\pm S D$ & - & $2.8 \pm 0.7$ & $3.1 \pm 0.7$ & $3.7 \pm 0.5$ & $3.5 \pm 0.6$ & $4.3 \pm 0.98$ \\
\hline $\begin{array}{l}\text { Percent positive, \% } \\
\text { range }\end{array}$ & - & $48.6(43.6-53.6)$ & $55.9(50.9-60.9)$ & $62.8(57.9-67.7)$ & $63.9(59.0-68.8)$ & $83.9(79.3-88.5)$ \\
\hline \multicolumn{7}{|l|}{ Gender } \\
\hline Male & $114(37.3)$ & $60 \quad(42.3) \S$ & $56 \quad(35.2)$ & $66 \quad(37.3)$ & $65 \quad(35.9)$ & $80 \quad(38.6)$ \\
\hline Female & $192(62.7)$ & $82 \quad(57.8)$ & $103(64.8)$ & $111(62.7)$ & $116(64.1)$ & $127(61.3)$ \\
\hline \multicolumn{7}{|l|}{ Age } \\
\hline $18-24$ yrs & $39 \quad(13.3)$ & $20(15.2)$ & $15 \quad(10.1)$ & $21(12.5)$ & 21 (12.3) & $28(14.0)$ \\
\hline $25-44$ yrs & $140(47.8)$ & $61 \quad(46.2)$ & 75 (50.3) & 78 (46.4) & $83 \quad(48.5)$ & 97 (48.5) \\
\hline $45-64$ yrs & $77 \quad(26.3)$ & $28 \quad(21.2)$ & $37 \quad(24.8)$ & $47 \quad(28.0)$ & $46 \quad(26.9)$ & $48 \quad(24.0)$ \\
\hline 65 yrst & $37 \quad(12.6)$ & $23(17.4)$ & $22(14.8)$ & $22(13.1)$ & $21 \quad(12.3)$ & $27 \quad(13.5)$ \\
\hline \multicolumn{7}{|l|}{ Race } \\
\hline Black African & $89 \quad(29.2)$ & 39 (27.7) & 42 (26.4) & $51 \quad(29.1) \S$ & $47(26.1) \S$ & $45 \quad(21.7)$ \\
\hline White & $198(64.9)$ & $91 \quad(64.5)$ & $103(64.8)$ & $109(62.3)$ & $117(65.0)$ & $145(70.0)$ \\
\hline Colored or Mixed & $18 \quad(5.9)$ & $11(7.8)$ & 14 (8.8) & 15 (8.6) & 16 (8.9) & 17 (8.2) \\
\hline \multicolumn{7}{|l|}{ Employment status } \\
\hline Employed & $115(39)$ & $53 \quad(38.4)$ & $57 \quad(37.7)$ & $65 \quad(38.9)$ & 68 (39.3) & 79 (38.9) \\
\hline Unemployed & $135(45.8)$ & $59 \quad(42.8)$ & $67 \quad(44.4)$ & $75 \quad(44.9)$ & $79 \quad(45.7)$ & 89 (43.8) \\
\hline Retired & $45 \quad(15.2)$ & $26 \quad(18.8)$ & $27 \quad(17.8)$ & 27 (16.2) & $26 \quad(15.0)$ & $35 \quad(17.2)$ \\
\hline \multicolumn{7}{|l|}{ Educational level } \\
\hline $\begin{array}{l}\text { Less than high school } \\
\text { (GR 12) }\end{array}$ & $40 \quad(14.2)$ & 19 (14.5) & $19(13.1)$ & $23(14.3)$ & 27 (16.6) & $26(13.2)$ \\
\hline $\begin{array}{l}\text { High school } \\
\text { graduate or } \\
\text { vocational training }\end{array}$ & $148(52.5)$ & $70 \quad(53.4)$ & 79 & $87 \quad(54.0)$ & $83 \quad(50.9)$ & $98 \quad(50.0)$ \\
\hline $\begin{array}{l}\text { College graduate or } \\
\text { higher }\end{array}$ & $94 \quad(33.3)$ & $42 \quad(32.1)$ & $47 \quad(32.4)$ & $51 \quad(31.7)$ & $53 \quad(32.5)$ & $72(37.7)$ \\
\hline \multicolumn{7}{|l|}{ Children } \\
\hline Yes & $202(67.8)$ & $91 \quad(65.5)$ & $104(67.5)$ & $117(68.8)$ & $117(66.1)$ & $134(65.6)$ \\
\hline No & $96 \quad(32.2)$ & $48 \quad(34.5)$ & $50 \quad(32.5)$ & $53 \quad(31.2)$ & $60 \quad(33.9)$ & $70 \quad(34.31)$ \\
\hline \multicolumn{7}{|l|}{ Marital status } \\
\hline Single-never married & $112(36.1)$ & $41 \quad(28.9)$ & $52(32.1)$ & $60 \quad(33.7)$ & $59 \quad(32.2)$ & $63 \quad(31.9)$ \\
\hline $\begin{array}{l}\text { Married or civil } \\
\text { partnership }\end{array}$ & $108(34.9)$ & $58 \quad(40.8)$ & $58 \quad(35.8)$ & $68 \quad(38.2)$ & $69 \quad(37.7)$ & 71 (36.0) \\
\hline $\begin{array}{l}\text { Divorced, separated } \\
\text { or widowed }\end{array}$ & $90 \quad(29)$ & $43 \quad(30.3)$ & $52(32.1)$ & $50 \quad(28.1)$ & $55 \quad(30.1)$ & $63 \quad(31.9)$ \\
\hline \multicolumn{7}{|l|}{ Annual household income } \\
\hline Low income $(<R 50,000)$ & $148(57.8)$ & $60 \quad(51.7)$ & $80 \quad(59.3)$ & 88 (60.3) & $92 \quad(59.7)$ & $99 \quad(576.5$ \\
\hline $\begin{array}{l}\text { Middle income } \\
\text { (R50,000 to } 149,999)\end{array}$ & 61 (23.8) & 32 (27.6) & $29(21.4)$ & $30 \quad(20.5)$ & $36 \quad(23.4)$ & 41 (23.8) \\
\hline $\begin{array}{l}\text { High income } \\
\text { (R150,000+) }\end{array}$ & $47 \quad(18.4)$ & $24 \quad(20.7)$ & 26 (19.3) & 28 (19.2) & $26 \quad(16.9)$ & 32 (18.6) \\
\hline \multicolumn{7}{|l|}{ Last dental visit (Time) } \\
\hline Less than 12 months & $228(52.2)$ & $113(60.1)$ & $126(59.2)$ & $137(58.6)$ & $141(59.2)$ & $128(61.2)$ \\
\hline More than 12 months & $179(41)$ & $75 \quad(39.9)$ & $87 \quad(40.8)$ & $97 \quad(41.4)$ & $97 \quad(40.8)$ & $81 \quad(38.7)$ \\
\hline $\begin{array}{l}\text { No previous } \\
\text { dental visit }\end{array}$ & $30(6.8)$ & $0 \quad(0.0)$ & $0 \quad(0.0)$ & $0 \quad(0.0)$ & $\begin{array}{ll}0 & (0.0)\end{array}$ & $0 \quad(0.0)$ \\
\hline \multicolumn{7}{|c|}{ Last dental visit (Location) } \\
\hline $\begin{array}{l}\text { State dental } \\
\text { clinic }\end{array}$ & $252(57.7)$ & 109 (58.3) & $134(63.2)$ & $151(64.8) \S$ & $150(63.2)$ & $128(61.8)$ \\
\hline Private dental clinic & $147(33.6)$ & 72 (38.5) & 70 & 77 (33.1) & $80 \quad(33.8)$ & 73 (35.2) \\
\hline $\begin{array}{l}\text { Other. e.g. } \\
\text { non-licensed }\end{array}$ & 38 (8.7) & $6 \quad(3.2)$ & $8 \quad(3.8)$ & $5 \quad(2.1)$ & $7 \quad(3.0)$ & $6 \quad(2.9)$ \\
\hline \multicolumn{7}{|c|}{ Satisfaction with last dental visit } \\
\hline $\begin{array}{l}\text { Extremely satisfied } \\
\text { or satisfied }\end{array}$ & $295(69.1)$ & $149(80.1) \S$ & $157(74.8) \S$ & $185(79.7) \S$ & $186(79.2) \S$ & $162(77.8) \S$ \\
\hline Neutral & 76 (17.8) & 21 (11.3) & $37 \quad(17.6)$ & $25(10.8)$ & 32 (13.6) & $30(14.4)$ \\
\hline $\begin{array}{l}\text { Dissatisfied and } \\
\text { extremely dissatisfied }\end{array}$ & 56 (13.1) & $16(8.6)$ & $16(7.6)$ & $22(9.5)$ & $17(7.2)$ & $16(7.6)$ \\
\hline
\end{tabular}




\begin{tabular}{|c|c|c|c|c|c|c|}
\hline Characteristic & Total, $N(\%)$ & Access to care & $\begin{array}{l}\text { Technical } \\
\text { quality }\end{array}$ & $\begin{array}{l}\text { Structure \& } \\
\text { facilities }\end{array}$ & Communication & $\begin{array}{c}\text { Global safety } \\
\text { rating }\end{array}$ \\
\hline \multicolumn{7}{|l|}{ Oral health status } \\
\hline $\begin{array}{l}\text { Satisfied with dental } \\
\text { health }\end{array}$ & $184(42.3)$ & 88 (46.8) & $97 \quad(45.5)$ & $100(42.7)$ & $115(48.5) \S$ & $100(48.0) \S$ \\
\hline $\begin{array}{l}\text { Not satisfied with } \\
\text { dental health }\end{array}$ & $251(57.7)$ & $100(53.2)$ & $116(54.5)$ & $134(57.3)$ & $122(51.5)$ & $108(51.9)$ \\
\hline \multicolumn{7}{|l|}{ General health status } \\
\hline $\begin{array}{l}\text { Satisfied with } \\
\text { overall health }\end{array}$ & 369 (85.2) & $167(88.8)$ & $189(88.3)$ & $202(86.0)$ & $213(89.5) \S$ & $184(88.0)$ \\
\hline $\begin{array}{l}\text { Not satisfied with } \\
\text { overall health }\end{array}$ & 64 (14.8) & $21 \quad(11.2)$ & $25 \quad(11.7)$ & 33 (14.0) & 25 (10.5) & 25 (11.96) \\
\hline \multicolumn{7}{|l|}{ Oral hygiene habits } \\
\hline $\begin{array}{l}\text { Clean teeth at least } \\
\text { once daily }\end{array}$ & 349 (94.3) & 157 (97.5) & $173(94.5)$ & $192(97.0)$ & $193(97.0)$ & 189 (95.4) \\
\hline $\begin{array}{l}\text { Clean teeth less than } \\
\text { once daily }\end{array}$ & $21 \quad(5.7)$ & $4 \quad(2.5)$ & $10(5.5)$ & $6 \quad(3.0)$ & $6 \quad(3.0)$ & $9 \quad(4.5)$ \\
\hline \multicolumn{7}{|l|}{ Cleaning product } \\
\hline $\begin{array}{l}\text { Toothbrush and } \\
\text { fluoride toothpaste } \\
\text { or non-fluoride } \\
\text { toothpaste }\end{array}$ & $212(57.3)$ & $57 \quad(35.2)$ & 78 (42.4) & $80 \quad(40.6)$ & $80 \quad(40.2)$ & 66 (33.6) \\
\hline $\begin{array}{l}\text { Others. e.g. } \\
\text { Chew-stick }\end{array}$ & $158(42.7)$ & $105(64.8)$ & $106(57.6)$ & $117(59.4)$ & $119(59.8)$ & $130(66.3)$ \\
\hline \multicolumn{7}{|l|}{ DAE experience } \\
\hline Experienced no DAE & $240(54.5)$ & $102(54.0)$ & $117(54.7) \S$ & $127(53.8) \S$ & $126(52.7) \S$ & $91 \quad(43.5) \S$ \\
\hline $\begin{array}{l}\text { Experienced one or } \\
\text { more DAEs }\end{array}$ & $200(45.5)$ & 87 (46.0) & $97 \quad(45.3)$ & $109(46.2)$ & $113(47.3)$ & $118(56.4)$ \\
\hline \multicolumn{7}{|c|}{$\begin{array}{l}\text { *Binary variables for patient-reported dimensions of quality were obtained by categorizing constructs into " } 1 \text { " High quality (above the mean of } \\
\text { collapsed items within that construct) and "0" Low quality (below the mean of collapsed items within that construct); Percentages represent the } \\
\text { proportion of participants who rated the dimension of quality and safety as high. } \\
\S \text { Significant } p \text {-values } \leq 0.05 \text { for Chi-squared }\left(\chi^{2}\right) \text { or Fisher's Exact Test. }\end{array}$} \\
\hline
\end{tabular}

Positive perception of quality by dimension $83.9 \%$

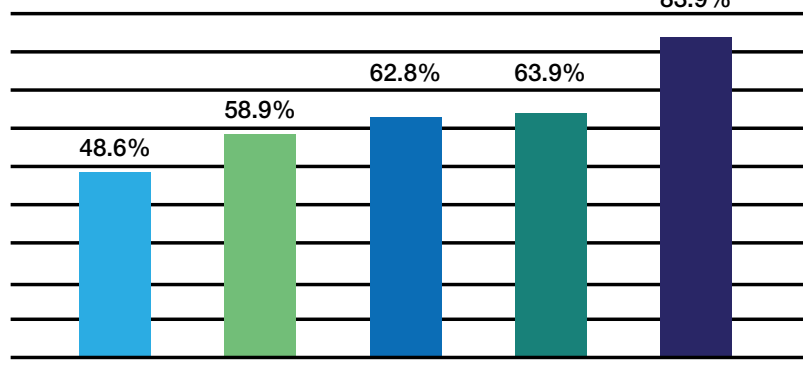

Figure 2. Positive perception of dental quality and safety by dimension.

Legend:

Technical quality, efficiency and effective
organization of care
Structure and facilities
Communication information and courtesy
Global rating of safety

Description: Bar chart illustrating the five dimensions of quality and the percentage of patients who had positive perceptions of each dimension. Access to care had the lowest rating (48.6\%); while an overwhelming number of patients rated safety as very high (83.9\%).

\section{Dimensions of quality and associated factors}

Initial bivariate analysis using Pearson's chi-squared $(\chi 2)$ test identified significant associations between:

a) Access to care and gender, satisfaction with last dental visit;

b) Technical quality and satisfaction with last dental visit, past DAE experience; c) Facilities and race, location of last dental visit, satisfaction with last dental visit, past DAE experience;

d) Communication and race, satisfaction with last dental visit, oral health status, general health status, past DAE experience:

e) Global safety rating and satisfaction with last dental visit, oral health status, past DAE experience.

Satisfaction with last dental visit was significantly associated with all the dimensions of quality and safety; followed by past DAE experience, which was associated with all factors except access to care (Table 3).

The factors that were significantly associated with the dimensions of quality and safety after controlling for other covariates in the generalized linear model.

\section{a) Access to care}

Participants who had a high school, vocational (PRR: 0.64; P: 0.04) or college education (PRR: 0.41; P:<0.001), visited the dentist more than 12 months prior (PRR: 0.7 ; P: 0.03), and experienced one or more DAEs (PRR: 0.7; P: 0.02) were less likely to rate the access to care as high.

On the contrary, high income (Adjusted PRR: 1.65; P: 0.03), married (PRR: 2.63; P: <0.001) or divorced (PRR: 2.3; P: <0.001) participants who had children (PRR: 2.25; P: <0.001) and visited private dental clinics (PRR: 1.45; P: 0.02), were more likely to rate the access to care as high. 


\section{b) Technical quality}

Similarly, participants who were middle-aged (25-44yrs) (PRR: 2.11; P: 0.02); 45-64 yrs (PRR: 2.18; P: 0.03)) coloured or mixed race (PRR: 2.01; P: 0.01), high school or vocational school graduates (PRR: 1.79; P: 0.04), and cleaned their teeth less than once daily (PRR: 2.05; $P$ : 0.01), were more likely to rate the technical quality as high. Individuals who had at least one dental visit in the preceding 12 months (PRR: 0.69; P: 0.04) were less likely to rate the technical quality as high.

\section{c) Structure and facilities}

Participants who were neutral about their last dental visit (PRR: 20.29; P: <0.001), visited a non-licensed dental provider (PRR: $<0.01 ; \mathrm{P}:<0.001$ ) and belonged to the middle income (R50, 000 to R149, 000 (PRR: 0.65; $P$ : 0.02)) economic bracket, had negative perceptions of the quality of the structure and facilities at the dental clinic. Retired participants (PRR: 1.62; P: 0.01) had positive perceptions of the quality of the structure and facilities at dental clinics.

\section{d) Communication}

Having a dental visit more than 12 months ago (PRR: 0.71 ; P: 0.02), and being neutral (PRR: 0.58; P: 0.01) or dissatisfied (PRR: 0.46; P: 0.02) with the last dental visit was associated with a decreased likelihood of rating the quality of communication as high.

\section{e) Global safety rating}

Participants who were dissatisfied or extremely dissatisfied (PRR: 0.59; P: 0.03)) with their last dental visits had a decreased likelihood of rating the overall safety of dental clinics as high.

\section{DISCUSSION}

Our results reveal a sub-optimal perception of dental quality among South African dental patients. $41.4 \%$ of participants did not view the services received at dental clinics as high quality. Compared with their counterparts in the United Kingdom (UK), they fared worse, where $20 \%$ of UK respondents rated their care as sub-optimal. ${ }^{35}$

When categorized into specific dimensions of quality, access to care received the lowest quality rating from $51.4 \%$ of participants. This calls for more attention by dental stakeholders in South Africa, especially as 'access to care' was mentioned as the most important factor affecting a patient's perception of dental quality in the UK as well. ${ }^{35}$ Despite this fair overall rating of quality, it is important to note that majority of participants (83.9\%) rated the dental clinics as "safe" or "extremely safe".

This high global rating is consistent with expectations because patients tend to be skewed towards the more positive response options when asked about overall healthcare ratings. ${ }^{9}$ Their true care experiences are usually highlighted when pressed for the details about specific aspects of care, such as waiting times and medication errors. ${ }^{9}$ In this study, there was no correlation between the overall perception of safety and the actual experiences of DAEs by participants, which underscores this theory even further.
Participants who had a previous DAE experience were less likely to rate the quality of access to dental care as high. Duplicate tests, poor wait times and the difficulty in getting emergency appointments received the most negative responses while clinic cleanliness/hygiene and staff courtesy/ respect received the most positive responses. These findings compare with a study about patient-reported measures of quality from five countries (United States, Australia, Canada, New Zealand, and United Kingdom). ${ }^{36}$

The UK (36\%) and Canada (37\%) ranked lowest on emergency waiting times, while the US ranked last on efficiency because patients had to repeat tests multiple times $(22 \%)$, or repeat their medical history to multiple providers (57\%). ${ }^{36}$ Another study in the US identified waits and delays, poor communication, and problems with the environment and amenities as the most commonly reported problems with service quality. ${ }^{16}$

They also found that despite the high incidence of service quality incidents, the patients (two-thirds) still rated the overall quality of care as excellent, which again confirms the theory that global ratings are skewed towards more positive responses. ${ }^{16}$

One explanation given was that patients consider their overall hospital experience when giving global ratings and this may not capture good experiences, such as emotional support or favorable clinical outcomes, that were not covered in the survey questions. ${ }^{16}$

Patient satisfaction emerged as the factor most associated with an increased positive perception of quality across all five dimensions of quality and safety (bivariate analysis). While satisfaction has been intricately linked to the perception of quality, ${ }^{11,37}$ it is but one perception of quality that is predominantly affected by one's expectations. ${ }^{38}$ The conceptual framework described by Sofaer et al. identified sociocultural norms, previous experiences, personal characteristics, knowledge of what to expect, extent of choice, patient needs, and reputation of provider as the baseline factors influencing patient expectations. $^{9}$

They surmised that patient expectations and patient experiences of care were the primary influencing factors on a patient's perception of care, which ultimately affects their definition and perception of quality. ${ }^{9}$ The degree to which one's perception is affected by expectations and/ or experiences varies between individuals and over time within-person. ${ }^{9}$

In dealing with this issue, Sixma et al. demonstrated that a more reliable approach was to look at an algorithm of performance, importance and impact scores for the various aspects of healthcare. ${ }^{1}$ Sixma's conceptual framework was based on the prior work of Zastowny et al. ${ }^{39}$ in the Patient Experience Survey (PES) and has influenced the development of instruments, such as the QUOTE 20-22,40-44 (Quality Of care Through the patient's Eyes) and CQI (Consumer Quality Index), ${ }^{19,23,45-50}$ for assessing patient-reported care quality across various disciplines. Dentistry is yet to develop a validated patient-reporting instrument of its own. 
In this study, patient characteristics such as age (middle-aged), race (coloured or mixed), marital status (married, divorced), child status (no children), employment status (retired), household income (>R150, 000 or 9200 USD) and educational status (high school or vocational education) were associated with an increased likelihood of having a better experience of care and higher rating of quality.

This is similar to findings from another study where being older, less educated, married and of a high social status was significantly associated with greater patient satisfaction. ${ }^{51}$

One explanation for this finding is that healthcare providers tend to be more respectful and responsive to the needs of middle-aged or older patients compared to younger ones as well as wealthier individuals. ${ }^{51}$

Perhaps, on the contrary, highly educated and single patients have greater expectations of care quality and apply more stringent assessments to their ratings of care quality compared with less educated and married individuals. In a study by Haviland et al., race was also found to be a significant factor affecting one's rating of healthcare services. ${ }^{52}$ This was consistent with findings by Tickle et al. among dental patients in the UK. ${ }^{35}$

Although our expectation was that the 'white' population would have higher ratings of care quality due to tenuous racial history of the sub-region ${ }^{53}$, it was the "colored or mixed' race that had significantly higher ratings of care quality (technical quality and effectiveness). This calls for a further exploration of the impact of socio-demographic variables on patients' perceptions of dental quality.

\section{CONCLUSION}

Patient perceptions of quality offer an insight into our performance as dental providers. The degree to which the patient's needs and expectations are met often determines their perceptions of quality. Our study findings suggest that the dental profession has huge challenges in meeting these expectations.

Working to develop standardized instruments for dentistry will afford researchers the opportunity to assess patient experiences of dental care quality more reliably rather than just being limited to patient satisfaction measures. In the end, providing care that is patientcentered is an indication of quality and that should be our ultimate goal.

\section{Acknowledgements}

Many thanks to Sister Magda Groenewald (Registered Nurse) who assisted with the distribution and collecion of research instruments from patients at the research site.

Special thanks to John Choi who was responsible for the data entry into REDCap and to Japneet Kwatra and Alfa Yansane, members of the Department of Oral Health Policy and Epidemiology, Harvard School of Dental Medicine, who assisted with the data cleaning and preparation for analysis.

\section{References}

1. Sixma HJ, Kerssens JJ, Campen Cv, Peters L. Quality of care from the patients' perspective: from theoretical concept to a new measuring instrument. Health Expectations 1998; 1(2): 82-95.

2. Committee on Healthcare Quality in America. Institute of Medicine (IOM). Crossing the Quality Chasm: A new health system for the $21^{\text {st }}$ century: The National Academies Press; 2001.

3. Shaller D. Patient-centered Care: What Does it Take? Report for the Picker Institute and the Commonwealth Fund. New York: The Commonwealth Fund; 2007.

4. National Institute for Clinical Excellence. Patient experience in adult NHS services: improving the experience of care for people using adult NHS services. Chapter 5: Themes for patient experience recommendations and quality standards. NICE Clinical Guideline 2012; 138.

5. Gerteis M. Through the patient's eyes: understanding and promoting patient-centered care: Jossey-Bass Inc Pub; 1993.

6. Coulter A. What do patients and the public want from primary care? British Medical Journal 2005; 331(7526): 1199-201.

7. Papp R, Borbas I, Dobos E, Bredehorst M, Jaruseviciene L, Vehko T, et al. Perceptions of quality in primary health care: perspectives of patients and professionals based on focus group discussions. BMC Family Practice 2014; 15(1): 128.

8. Laine C, Davidoff F, Lewis CE, Nelson EC, Nelson E, Kessler RC, et al. Important elements of outpatient care: a comparison of patients' and physicians' opinions. Ann Intern Med. 1996; 125(8): 640-5.

9. Sofaer S, Firminger K. Patient perceptions of the quality of health services. Annu Rev Public Health. 2005; 26: 513-59.

10. Hibbard JH, Peters E. Supporting Informed Consumer Health Care Decisions: Data Presentation Approaches that Facilitate the Use of Information in Choice. Annual Review of Public Health. 2003; 24(1): 413-33.

11. Cleary PD, McNeil BJ. Patient satisfaction as an indicator of quality care. Inquiry: a Journal of Medical Care Organization, Provision and Financing 1988; 25(1): 25-36.

12. Coulter A. After Bristol: putting patients at the centre. British Medical Journal 2002; 324(7338): 648-51.

13. Golin CE, DiMatteo MR, Gelberg L. The role of patient participation in the doctor visit. Implications for adherence to diabetes care. Diabetes Care 1996; 19(10): 1153-64.

14. Taylor DM, Wolfe R, Cameron PA. Complaints from emergency department patients largely result from treatment and communication problems. Emergency Medicine 2002; 14(1): 43-9.

15. Hickson GB, Clayton EW, Githens PB, Sloan FA. Factors that prompted families to file medical malpractice claims following perinatal injuries. JAMA. 1992; 267(10): 1359-63.

16. Weingart SN, Pagovich O, Sands DZ, Li JM, Aronson MD, Davis RB, et al. Patient-reported service quality on a medicine unit. International Journal for Quality in Health Care 2006; 18(2): 95-101.

17. Delbanco TL. Quality of care through the patient's eyes. British Medical Journal 1996; 313(7061): 832-3.

18. Crow R, Gage H, Hampson S, Hart J, Kimber A, Storey $L$, et al. The measurement of satisfaction with healthcare: implications for practice from a systematic review of the literature. Health Technology Assessment (Winchester, England) 2002; 6(32): 1-244.

19. Damman OC, Hendriks M, Sixma HJ. Towards more patient centred healthcare: A new Consumer Quality Index instrument to assess patients' experiences with breast care. European Journal of Cancer (Oxford, England 1990) 2009; 45(9): 1569-77.

20. de Kok M, Scholte RW, Sixma HJ, van der Weijden T, Spijkers KF, van de Velde CJH, et al. The patient's perspective of the quality of breast cancer care: The development of an instrument to measure quality of care through focus groups and concept mapping with breast 
cancer patients. European Journal of Cancer 2007; 43(8): 1257-64.

21. Nijkamp MD, Sixma HJ, Afman H, Hiddema F, Koopmans SA, van den Borne B, et al. Quality of care from the perspective of the cataract patient: QUOTE cataract questionnaire. Journal of Cataract and Refractive Surgery 2002; 28(11): 1924-31.

22. Nijman JL, Sixma H, Triest Bv, Keus RB, Hendriks M. The quality of radiation care: The results of focus group interviews and concept mapping to explore the patient's perspective. Radiotherapy and Oncology 2012; 102(1): 154-60.

23. Sixma $H$, Hendriks M, de Boer D, Delnoij D. Manual CQI instruments. An instruction for the development and use of Consumer Quality Index (CQI) questionnaires. Centrum Klantervaring Zorg (Dutch Centre for Consumer Experience in Health Care), Utrecht. 2008.

24. Mills I, Frost J, Kay E, Moles DR. Person-centred care in dentistry - the patients' perspective. British Dental Journal 2015; 218(7): 407-13

25. Campbell S, Tickle M. How do we improve quality in primary dental care? British Dental Journal 2013; 215(5): 239-43.

26. Tickle M, Campbell S. How do we measure quality in primary dental care? British Dental Journal 2013; 215(4): 183-7.

27. Mills I, Frost J, Moles DR, Kay E. Patient-centred care in general dental practice: sound sense or soundbite? British Dental Journal 2013; 215(2): 81-5.

28. Hibbard JH, Greene J. What the evidence shows about patient activation: better health outcomes and care experiences; fewer data on costs. Health Affairs 2013; 32(2): 207-14

29. Hunt RJ, Krishna Aravamudhan B. The quality movement in oral health care. The Journal of the American Dental Association 2014; 145(5): 421-3.

30. Dental Quality Alliance. Advisory Committee on Education and Communication. Quality Measurement in Dentistry: a Guidebook. American Dental Association; 2012.

31. Mills I, Batchelor P. Quality indicators: the rationale behind their use in NHS dentistry. British Dental Journal 2011; 211(1): 11-5.

32. Finance Commercial and NHS Directorate, NHS Group, Legislation and Policy Unit, Dental and Eyecare Services Cost Centre 17181. Dental Quality and Outcomes Framework for 2015-16. In: Department of Health, editor. United Kingdom: Crown Copyright; 2016.

33. Bhardwaj A, Ramoni R, Kalenderian E, Neumann A, Hebballi NB, White JM, et al. Measuring up: Implementing a dental quality measure in the electronic health record context. Journal of the American Dental Association (1939) 2016; 147(1): 35-40.

34. Cleary PD. The increasing importance of patient surveys. Quality in Health Care 1999; 8(4): 212.

35. Tickle M, O' Malley L, Brocklehurst P, Glenny AM, Walsh T, Campbell S. A national survey of the public's views on quality in dental care. British Dental Journal 2015; 219(3): E1-E.

36. Davis K, Fund C. Mirror, mirror on the wall: Looking at the quality of American health care through the patient's lens: Commonwealth Fund; 2004

37. Williams B. Patient satisfaction: a valid concept? Soc Sci Med. 1994; 38(4): 509-16.

38. Sitzia J, Wood N. Patient satisfaction: a review of issues and concepts. Soc Sci Med. 1997; 45(12): 1829-43.

39. Zastowny TR, Stratmann WC, Adams EH, Fox ML. Patient satisfaction and experience with health services and quality of care. Quality Management in Health Care 1995; 3(3): 50-61.
40. Soares JB, Nogueira MC, Fernandes D, Goncalves BM, Goncalves R. Validation of the Portuguese version of a questionnaire to measure Quality of Care Through the Eyes of Patients with Inflammatory Bowel Disease (QUOTE-IBD). European Journal of Gastroenterology and Hepatology 2015; 27(12): 1409-17.

41. Oh J, Cho H, Kim YY, Park HJ, Kim HK. An integrative review on development of "Quality of care Through the Patients' Eyes" (QUOTE) Instruments. Journal of Nursing Care Quality 2015; 30(4): E26-31.

42. Gutteling JJ, de Man RA, Busschbach JJ, Darlington AS. Quality of health care and patient satisfaction in liver disease: the development and preliminary results of the QUOTE-Liver questionnaire. BMC Gastroenterology 2008; 8: 25.

43. van Weert JC, Jansen J, de Bruijn GJ, Noordman J, van Dulmen S, Bensing JM. QUOTEchemo: a patient-centred instrument to measure quality of communication preceding chemotherapy treatment through the patient's eyes. European Journal of Cancer (Oxford, England 1990). 2009; 45(17): 2967-76.

44. Hekkink CF, Sixma HJ, Wigersma L, Yzermans CJ, van der Meer JT, Bindels PJ, et al. QUOTE-HIV: an instrument for assessing quality of HIV care from the patients' perspective. Qual Saf Health Care. 2003; 12(3): 188-93.

45. van Cranenburgh OD, Krol MW, Hendriks MC, de Rie MA, Smets EM, de Korte J, et al. Consumer Quality Index Chronic Skin Disease (CQI-CSD): a new instrument to measure quality of care from the patient's perspective. The British Journal of Dermatology 2015; 173(4): 1032-40.

46. Stubbe JH, Brouwer W, Delnoij DM. Patients' experiences with quality of hospital care: the Consumer Quality Index Cataract Questionnaire. BMC Ophthalmology 2007; 7: 14.

47. Claessen SJ, Francke AL, Sixma HJ, de Veer AJ, Deliens L. Measuring patients' experiences with palliative care: the Consumer Quality Index Palliative Care. British Medical Journal Supportive and Palliative Care 2012; 2(4): 367-72.

48. Zuidgeest M, Sixma H, Rademakers J. Measuring patients' experiences with rheumatic care: the Consumer Quality Index rheumatoid arthritis. Rheumatology international 2009; 30(2): 159-67

49. Bos N, Sturms LM, Schrijvers AJ, van Stel HF. The Consumer Quality Index (CQ-Index) in an accident and emergency department: development and first evaluation. BMC Health Services Research 2012; 12: 284.

50. Delnoij DM, Rademakers JJ, Groenewegen PP. The Dutch Consumer Quality Index: an example of stakeholder involvement in indicator development. BMC Health Services Research 2010; 10(1): 88.

51. Hall JA, Dornan MC. Patient sociodemographic characteristics as predictors of satisfaction with medical care: a meta-analysis. Soc Sci Med. 1990; 30(7): 811-18.

52. Haviland MG, Morales LS, Reise SP, Hays RD. Do health care ratings differ by race or ethnicity? Joint Commission Journal on Quality and Safety 2003; 29(3): 134-45.

53. Coovadia H, Jewkes R, Barron P, Sanders D, Mclntyre D. The health and health system of South Africa: historical roots of current public health challenges. The Lancet 374(9692): 817-34. 